\title{
Research on the Pricing of Shared Ownership Housing
}

\author{
Dai Yuan $\mathrm{Li}^{1}$, Cong Wei Xie ${ }^{1}$, Shu Hao Chen ${ }^{1} \&$ Xiu Xiang Zou ${ }^{1}$ \\ ${ }^{1}$ Finance Department of International Business School, Jinan University, Zhuhai, China \\ Correspondence: Dai Yuan Li, Finance Department of International Business School, Jinan University, Zhuhai, China.
}

Received: November 6, 2018

Accepted: November 22, $2018 \quad$ Available online: December 4, 2018

doi:10.11114/aef.v6i1.3832

URL: https://doi.org/10.11114/aef.v6i1.3832

\begin{abstract}
To a great extent, the abnormal phenomena of profit making in speculation houses will disappear and the rigid housing demand of ordinary families will be resolved by shared ownership housing. Starting from the consumption structure of the target group of the shared ownership housing, this paper makes an in-depth analysis of the pilot cities that have implemented the shared ownership housing through literature review and data survey, empirically analyses the deviation degree of house rent and the unbalanced situation of residents' housing affordability, and studies the rent of the shared ownership housing and the unbalanced situation of residents' housing affordability through panel data model. Through the comprehensive index of housing affordability to find out the best proportion of the rent of shared ownership housing in the monthly income of young workers aged 20-35, and then get the monthly rent, give relevant feasible suggestions. The research shows that government departments should implement the common property right housing from the aspects of reducing land transferring fees and taxes, strengthening the qualification examination mechanism and so on.
\end{abstract}

Keywords: shared ownership housing, housing panel data model, housing affordability comprehensive index

\section{Introduction}

Since the comprehensive housing reforms starts in 1998, China's housing monetization reform and the government's policy of encouraging housing ownership have promoted the rapid development of the real estate market, and the real estate industry has entered a golden period of development. However, due to the long-term excessive emphasis on housing economic policy dimension and neglect of social policy dimension to meet housing demand, the two-way absence of housing supply efficiency and housing equity has occurred in the housing market. On the one hand, the sustained rise of housing prices makes housing an important channel for speculation, which leads to overheating of real estate investment and steady rise of house prices in China. At the same time, although low-income and middle-income families have limited affordability for commercial housing, their enthusiasm for access to housing has not decreased significantly. In this case, housing has become one of the "mountains" on the people's heads; on the other hand, the effect of the housing security system in China, represented by low-rent housing and economical house, has not been satisfactory. Housing inequality and the resulting wealth gap have become an important manifestation of social inequality, and even lead to social discontent, threatening social stability.

In the current housing security system, although the redefinition of the supply objects and modes of economical house helps to avoid some higher-income families seeking profits by purchasing economical house, the shrinkage of the supply objects has resulted in more people who are unable to enter the private market directly to buy houses and can not enjoy economical house. The "sandwich class" of subsidies appears to have little effect. Due to the controversy over fairness, economical house suffers a reputation crisis. Therefore, as a form of housing security that can be purchased, the economical house policy gradually fade out of government documents. Low rent housing security is oriented to low-income families, and there are limitations in the supply target. In order to solve the housing problem of "sandwich-layer" families, provide a multi-level housing security system, and to curb speculation and speculation in housing, in March 2007, the Huaian Municipal Party Committee and Municipal Government issued the "Opinions on the Implementation of Nine Major Projects for People's Livelihood Assistance" (Opinions on the Implementation of Huai'an Anju Project), which initiated the nature of land transfer nationwide. The common property rights housing security mode. In 2010, the government published the "Guidelines on Accelerating the Development of Public Rental Housing" document, which marked the beginning of the transformation of the form of housing security in the country from "rent-only" to "rent-only". After 2012, economical house, price-limited housing and other security policies to encourage low and medium-sized families to buy housing are declining. China's housing security policy has objectively 
corrected the drawbacks of overemphasizing housing ownership and neglected lease security in housing security from "sell-only-rent" to "rent-only-sale", which is helpful to enhance the pertinence of housing security and improve the efficiency of the use of public resources, and has certain rationality. However, some families with certain affordability are not satisfied with renting, they still hope to achieve housing ownership through the help of the government. Therefore, how to reduce the access threshold of the housing market, help low-income families to meet housing needs, so that they have the opportunity to share the results of the real estate market and economic development, has become a problem that some local governments need to consider. Against this background, shared ownership housing came into being in some areas.

\section{Literature Review}

Zhou Jie (2009) made innovations in the following two aspects: first, using the game model of economical house pricing to get the determinants of economical house price; second, by studying and drawing lessons from the successful experience of foreign public housing policy, he put forward the following proposals. The guarantee method of common property housing and housing voucher. However, due to the difficulty of data acquisition, it is not possible to analyze the pricing model of economical house for example. At the same time, the determination and definition of the consumer is also the content that needs further study. Deng Xiaopeng and Duan Haozhi (2012) made in-depth research on the property rights distribution among the public entities of economical house. The government departments, the guaranteed objects and private investors are the three main participants in the property rights distribution. This paper studies the initial distribution of property rights from the two aspects of "quantity" and "quality", and the redistribution of common property rights is reflected in the adjustment of property rights. Chen Fengli (2014) proposed that the initial allocation of property rights requires a clear proportion of property rights. The government and individuals should divide the property rights in proportion. At the same time, the joint property rights housing needs a flexible property rights adjustment mechanism to maximize its utility. Taking Huangshi City as an example, this paper makes an empirical analysis, and puts forward that the specific proportion of property rights is determined according to the income of the buyers. However, the author has not studied how to make the rent standard and set the adjustment coefficient. Shan Xueqin and Li Yanchao (2014) built a pricing model of public rental housing on the basis of the established role of public rent and cost, and took Chongqing as a city of empirical analysis to reach the target state of the government, builders and households. Zeng Jixiang (2013) designs the rent pricing model and subsidy mechanism of public rental housing, constructs regression equation, and takes Xin'an public rental housing project as an example for empirical analysis. This article holds that the formulation of rent price should be dynamic. Deng Hongqian and Wang Yubo (2015) proposed that rent pricing should not only consider the affordability of the guaranteed target, but also consider the factors of government cost recovery. Wang Yubo (2016), aiming at a series of problems existing in the pilot cities, believes that only by considering both the purchase price and the seller's price, can the common property rights housing be better promoted and operated. On the basis of "win win" between the government and the recipients, the pricing formula is given. Zhou Yi and Sun Xiao (2017) constructed the model under the BOT mode by using the net present value method. They considered that the three key gradient factors affecting the rent payment of common rental housing were the rental family, the public rental housing itself and the rental mode. Taking Wuhan public rental housing project as an example, this paper makes an empirical study and analysis, and puts forward that the allocation scheme of common property rights of public rental housing should be flexible and diversified. Rent pricing should adopt a dual-track system and implement the proposal of "separation of rent and compensation". Jiang Mindan, Zhang Fengping, etc. (2015) from the hypothesis model, analyzed the positive impact of the establishment of housing prices on users'purchase of common property rights housing. To a certain extent, their pricing can draw lessons from the pricing mechanism model of economical house, that is, their cost composition as the main factor to consider, so as to rationalize the pricing. Tang Xiaoxian (2012) made an in-depth analysis of Huai'an's shared property rights housing, affirmed the innovation and pointed out the controversy and shortcomings. In order to safeguard the interests of the people and solve the problem of low and middle income people's difficulty in buying houses, this paper puts forward suggestions and opinions on the further development of common property houses in Huai'an City. Prince Bo (2014) reveals the nature and concept of the common property right house. According to the property right theory, the system of the common property right house belongs to the mixed ownership. The biggest difference is that the land used for the common property right house is changed from allocation to transfer. At the same time, in the process of concrete implementation, the system of common property right house faces such problems as benefit distribution, exit mechanism, circulation and transaction, and purchase qualification certification. Penner (2014) believes that as a new form of policy-oriented housing, the common property right housing has depressed the profit-making space in time and guaranteed the interests of buyers in price, which makes it difficult for middle and low-income people to buy houses. The common property house needs to control the balance of interests so as to ensure fairness. Zhao Qing (2015) analyzed the problems in the implementation of the policy based on the common property right housing in Shanghai, and put forward policy suggestions in view of the problems, so as to achieve the ultimate goal of protecting the housing of middle and low 
income groups. Xu Hong (2017) takes Beijing as an example to discuss the development mode of the common property right housing, compares the development mode of several pilot projects, and draws the conclusion that the mode of the common property right housing in Beijing is inadequate. At the same time, through research and analysis, it is considered that the reasonable proportion of the share of property rights ranges from $50 \%$ to $70 \%$ for individuals and $30 \%$ to $50 \%$ for governments. In the early stage of operation, the proportion of property right share distribution can increase the proportion of individual purchase, which makes the proportion distribution more reasonable. Xu Zhichao and Zhang Qinglong (2018) adopt qualitative analysis method to analyze and discuss the pricing mechanism of four pricing links: selling price, rent pricing during the period of joint property rights, pricing of purchasing government-owned property rights after expiration, and withdrawal of buyers from joint property rights, starting from the construction cost of joint property houses and the affordability of buyers. The pricing of housing.Mount, I. (2015) expounds the existing knowledge, clarifies the dimensions of the intermediate housing market, and focuses on policy issues based on a large share of owners in the UK. LEE, H and RONALD, R. Expansion (2012) argue that public rental housing, on the one hand, takes care of the housing needs of very low-income or vulnerable families. On the other hand, more types of regular rent have been produced for wider income categories. Patrick W. Schmitz (2017) affirmed the advantages of co-ownership, believing that co-ownership is usually the best. When considering joint ownership, joint ownership based on bilateral veto is impossible to achieve the best, whether investment is human capital or physical capital. Richard Disney and Guannan Luo (2017) found that RTB can improve the overall welfare of low-income families only if the quality of the municipal council housing is low enough to give middle-income families insufficient incentive to implement RTB. STEGMAN, MA (2017) put forward three main points: first, there is an inseparable link between housing and rental market; second, the federal housing policy should achieve a more appropriate balance between housing and rent subsidies; third, on average, the income of rental households is about half of that of households with housing. ANDERSSON, R and TURNER, LM pointed out that from the 1930s to the 1990s, Swedish public housing was a key factor in the ambition of the Social Democratic Party to establish a housing system, which would ensure that everyone had access to high-quality, economical house. Susan Bright and Nicholas Hopkins argue that the rights and responsibilities of co-owners differ greatly from those of traditional homeowners in many respects, including their rights in value ownership. It argues that there is a need for a more subtle way to refer to family ownership and to change consumers'expectations of what sharing ownership means. HEGEDS, J, LUX, M, etc. (2017) outlined the private rental housing problems in some new EU Member States and other countries in transition. It is believed that this will be of great value to scholars and practitioners involved in housing policy and economy, urban development, international relations, political, economic and social sciences. Cowan, D (Cowan, Dave), Carr, H (Carr, Helen) discussed one aspect of the development of low-cost housing projects in the UK: shared ownership. The lease is the center of the development of shared ownership. It is transformed into a model lease and registered with other organizations, the most critical of which is the construction association.

A large number of literature studies show that, because of the few pilot cities in China, the policy of shared property rights housing is in the process of perfection, and there is not a large number of reliable data for example analysis, its research needs to be further in-depth. This paper is based on the research literature and field research and analysis, using the data of urban youth workers'consumption expenditure and housing information and real estate market data, according to the cost of housing construction and development and the housing capacity of urban residents, the optimal housing price-rent ratio can be obtained to effectively solve the housing problem of outstanding youth groups in China. Housing difficulties, retaining talent, stimulating local economic growth.

\section{Theoretical Analysis of Mutual Property House}

First of all, it needs to be clear that the direction of development of joint property housing is closed, circular and guaranteed. Closing means that the common property right housing is relatively isolated from the common listed commercial housing. Its purpose is to erase the commodity attribute of speculative arbitrage and the financial attribute of hedging, and return to the real value of housing - to meet the residents'living needs. Its circulation must be under the strong legal supervision, the transaction relationship of low purchase and high sale does not exist in the common property right housing; the security means that the pricing of the common property right housing is guaranteed, and the quality is guaranteed. The security of housing pricing requires that housing pricing should start from the individual residents and make them feel reasonable and relaxed. The quality of security requires that housing pricing should start from the individual residents and make them feel satisfied and comfortable. We must correct some deep-rooted "false concepts" - security means cheap, simple and low quality. Security means not only satisfying the basic living requirements of low-income people, but also satisfying the good living requirements of middle and high-income people. The "security" of common property housing refers to the second point. 
Table 1. Relevant policies of shared ownership housing issued by China in recent years

\begin{tabular}{|c|c|c|}
\hline Year & Policy & Content \\
\hline 9.2006 & Economical housing reform & Proposing a common property right \\
\hline 8.2007 & Huai'an pilot & $\begin{array}{l}\text { Low-income families and the government jointly holding } \\
\text { property rights }\end{array}$ \\
\hline 1.2012 & $\begin{array}{l}\text { Shanghai lowered the threshold for shared } \\
\text { ownership housing }\end{array}$ & Applying monthly income of 5,000 yuan \\
\hline 6.2014 & $\begin{array}{l}\text { Ministry of Housing and Urban-Rural } \\
\text { Development }\end{array}$ & $\begin{array}{l}\text { six cities in Beijing, Shanghai, Shenzhen, Chengdu, } \\
\text { Huai'an and Huangshi are national pilot cities for shared } \\
\text { property housing. }\end{array}$ \\
\hline 8.2014 & $\begin{array}{l}\text { Huai'an National } \\
\text { Common Property Housing Pilot Work } \\
\text { Implementation Plan }\end{array}$ & Stop building housing and change to monetary subsidy \\
\hline 4.2017 & $\begin{array}{l}\text { The Nanjing Municipal Government } \\
\text { issued the "Nanjing City Talents Housing } \\
\text { System (Trial)" }\end{array}$ & $\begin{array}{l}\text { Give eligible talent rental subsidies, and provide shared } \\
\text { property housing to solve the housing problem of } \\
\text { innovative and entrepreneurial talents }\end{array}$ \\
\hline 8.2017 & Beijing plans to implement new policies & New Beijingers are allocated no less than $30 \%$ \\
\hline 9.2017 & $\begin{array}{l}\text { Interim Measures for the Administration } \\
\text { of Shared Housing in Beijing }\end{array}$ & Closed operation, no transfer, no trading within 5 years \\
\hline 7.2018 & $\begin{array}{l}\text { Notice on the Relevant Matters } \\
\text { Concerning the Use of Personal Housing } \\
\text { Loans by Shareholders of Beijing }\end{array}$ & $\begin{array}{l}\text { Clarified the minimum down payment ratio of shared } \\
\text { equity housing loans, restricting transactions }\end{array}$ \\
\hline 8.2018 & $\begin{array}{l}\text { Launched the purchase of } 2141 \text { sets of } \\
\text { shared property rights in Beijing Haidian }\end{array}$ & $\begin{array}{l}\text { The average price of the whole decoration is } 37,800 \text { yuan } \\
\text { / building square meter, the proportion of the property } \\
\text { rights of the purchaser of a single set of houses is } 70 \% \text {, } \\
\text { and the shareholding of the government's property rights } \\
\text { shareholding is } 30 \% \text {. }\end{array}$ \\
\hline
\end{tabular}

Table 1 shows the relevant policies of the common property houses issued by China in recent years. This paper believes that in 2007, the country launched the six-city pilot shared property housing for the first time, including Huai'an, Shanghai, Shenzhen, Huangshi, Chengdu, and Beijing, which failed to attract widespread attention and achieved remarkable results. The main reasons for the results are three points:

(1) Adjustment of the national strategy. The outbreak and spread of the 2008 international financial crisis were the main incentives. The government launched a basket of economic stimulus plans, including the dual support of monetary and fiscal means, which played a significant role in China's economic recovery. Prosperous credit mainly flows to infrastructure construction and real estate development investment. At this time, regulating real estate prices is no longer the main policy objective of the government.

(2) The low-rent housing, two limited houses, and economical house will be piloted and promoted. The main advantage of the economical house and the two restricted houses is that they will completely transition to ordinary commercial housing during the second transfer. They will trade normally in the market, and the government departments will no longer be responsible for them and get rid of the cumbersome and heavy economic and legal burden. The city has built a large number of two restricted houses and affordable houses.

(3) The first appearance of the shared property house was cold, and the pilot was not successful. In October 2007, Huai'an City launched the first batch of 300 sets of shared property housing. These 300 houses are for self-employed buyers, not for resettlement. Households with housing difficulties in the resettlement households can also purchase shared property houses. These houses are scattered in the three districts of Xinxin Garden, Hongfu Community and Jiarun Court, with an average price of 2,300 yuan per square meter. At that time, the market price was about 2,500 yuan per square meter. However, from the news reports at the time, the first batch of shared property housing was launched as "cold". According to the design threshold at that time, families with a per capita income of less than 400 yuan/month can apply for shared property housing. A situation that followed was that there were many consultants, but there were very few real applications. As of December of that year, only 70 households were actually applied for. As of 2014, Huai'an City has stopped the construction of new shared property housing and changed to the form of money fund assistance.

The biggest revelation of the "Huai'an experience" is the major flaws in the pricing mechanism and the vague repetition of the property rights positioning. The shared property housing in Huai'an City is based on the pricing of commercial housing with the same construction conditions. The price itself is no different from the commercial housing. Under this circumstance, the government does not have sufficient funds to bear the market price, and the government holds a part of the property rights in the property houses. Huai'an Fangyi does not have the price advantage, and the second has no 
complete property rights. The buyers are powerless and have no intention of buying. It is natural to encounter cold. Judging from the experience of Huai'an, the policy formulation of shared property housing is easy to fall into the shackles of "assisted" purchase. The government is reluctant to give up the land transfer fee and the deed tax, property tax, land use tax and value added on the ordinary commercial housing. Taxes and business taxes are expected to be sold at market prices. The government only assumes the responsibility for purchasing assistance in the first stage of sales, and does not involve complex long-term management and troublesome property rights disputes. This fundamentally distort the original intention of the introduction of shared property houses. Two limited houses, affordable houses, public rental houses and shared property houses should not be completely market-traded goods. The government should maintain a strong presence from pricing to management to exit. The failure of the two limited houses and affordable houses is the biggest lesson. After entering the circulation phase, it quickly became an ordinary high-priced house, so that the policy itself evolved into a deformed speculative tool, which mixed the fish and the dragon, causing more serious loss of efficiency for those who really need housing.

\section{Study on Relationship Between Housing Price and Land Price Based on Panel Data Model}

The article thinks that the prices of commodity houses are mainly consisted of the following five parts:

(1) The cost of land acquisition, which mainly refers to the land grant. When mentions to the cost of land acquisition per square meter is the floor land price according to the plot ratio and the approval plan.

(2) Land tax, including the land purchase tax, tax of contract, planning fees;

(3)Construction and installation costs, mainly including the unimpeded water, electricity, road and communication as well as the smooth of construction cite, concrete, steel and so on;

(4) Enterprise operating expenses, including bank interest, sales costs, etc.;

(5) Corporate profits.

In this paper, we choose the land price lagging three phase to establish the analysis model. Due to the more complicated estimation of tax and the opacity of related details tax data, it is difficult to identify specific data by combining deed taxes, stamp duty, management expenses and fund expenses with other projects. The usual practice is to investigate the development project of some enterprises in the field, so as to calculate the burden and the taxes of the whole real estate industry. However, because of the business situation between the housing companies vary widely, the speculation is inevitably inaccurate. But it is no doubt that the burden of tax and land purchase costs and housing sales price growth grow year-on-year. Figure 1 shows houses prices and tax and fee for real estate industry in Beijing.

For the cost of building installation, the price differentiation is serious, but the cost difference between the building installation is not great enough to explain the huge differentiation of house price between regions. In 2014, the average housing price of Beijing, Shanghai, Shenzhen is 37416 yuan per square meters, 30591 yuan per square meters, 26559 yuan per square meters. And respectively, 36750 yuan per square meters, 33067 yuan per square meters, 35072 yuan per square meters in 2015, which are more than 30,000 yuan per square meters. From the cost point of view, the difference between different area is not so far different, locating in the 1300-2400 yuan per square meter interval, and has little change in two years.

Therefore, the panel fixed effect model of Beijing, Shanghai, Guangzhou and Shenzhen of four years(2017 to 2010) was established.

The general form of the single variance panel data model is:

$$
y_{i t}=x_{i t} \beta+z_{i} \delta+\mu_{i}+\varepsilon_{i t}
$$

Among them, $i$ denotes four cities in Beijing, Shanghai, Guangzhou and Shenzhen, $t$ denotes the time point of 2010-2017, $y_{i t}$ denotes the house price of $i$ at $t, X_{i t}$ denotes the floor price of $i$ at $t, Z_{i}$ denotes the individual characteristics of the city $i$ that do not change with time, And the disturbance term consists of two parts of $\mu_{i}+\varepsilon_{i t}$, of which $\mu_{i}$ denotes the intercept term of individual heterogeneity and $\varepsilon_{i t}$ denotes the independent and identically distributed random item.

In the model establishment, the paper removes the tax data with strong correlation with the land grant, the disturbance item must be strongly correlated with the explanatory variable. From the economic theory, it can be determined as the fixed effect panel model. The data of this paper is based on the study of Beijing, Shanghai, Guangzhou and Shenzhen these four cities, which originates from China land price data, Beijing Economic Statistical Yearbook, Shanghai Economic Statistical Yearbook, Guangzhou Economic Statistical Yearbook and Shenzhen Economic Statistical Yearbook, which is the balance panel data. Using STATA software, the panel analysis is as follows: 


\begin{tabular}{ccccc}
\hline Standardization $\mathrm{R}$ & Intra group $=0.6364$ & \multicolumn{2}{c}{ Inter group $=0.4270$} & \multicolumn{2}{c}{ Population $=0.5735$} \\
\hline cor $\left(\mathrm{u} \_\mathrm{i}, \mathrm{Xb}\right)=0.031$ & $\mathrm{~F}(1,27)=47.25$ & \multicolumn{3}{c}{ Prob $>\mathrm{F}=0.0000$} \\
\hline House price & Coefficient & Standard deviation & $\mathrm{T}$ test & $\mathrm{P}>|\mathrm{t}|$ \\
\hline Floor land price & .9080182 & .1320902 & 6.87 & 0.000 \\
\hline cons & 13549.48 & 2622.946 & 5.17 & 0.000 \\
\hline sigma_u & \multicolumn{5}{c}{5609.464} \\
\hline sigma_e & \multicolumn{5}{c}{6465.5074} \\
\hline rho & \multicolumn{5}{c}{ (f294605 } & (fraction of variance due to $\mathrm{u} \_\mathrm{i}$ ) $\mathrm{F}=0.0028$
\end{tabular}

Firstly, using the intra-group estimator, we get the t-test of the average individual effect and the factors of the floor land price. The t-test is $\mathrm{P}=0.00$ which far less than the confidence probability of 0.05 , and the parameters are remarkably effective. The goodness of fit of intra-group, inter-group and total are $0.427,0.6364$ and 0.5735 , respectively, which are more than $20 \%$, thus can be considered as fairly good fitting degree. The test also shows that the variance of the compound disturbance mainly comes from the change of the individual effect.In order to get the results of individual factors in every cities, the LSDV method was used to further investigation.

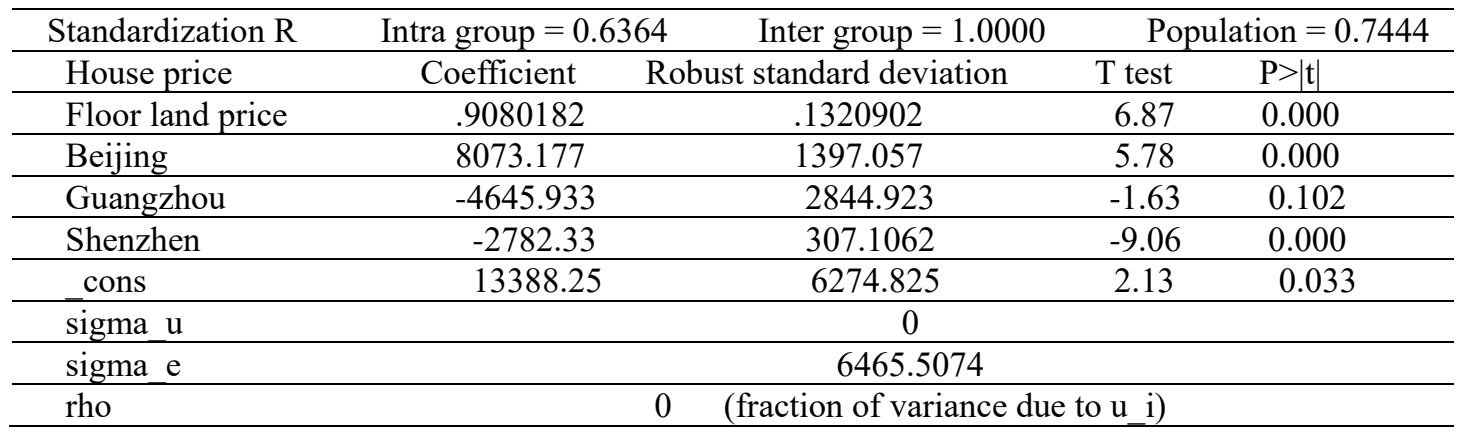

The test of urban individual virtual variables in Beijing and Shenzhen is very remarkable, $\mathrm{P}=0.00<0.05$, while the difference test in Guangzhou is not very obvious. If the time effect is taken into consideration, a two-way time effect analysis will be conducted in 2010 as a base period:

\begin{tabular}{|c|c|c|c|c|}
\hline Standardization $\mathrm{R}$ & Intra group $=0.8621$ & Inter group $=0.4270$ & \multicolumn{2}{|c|}{ Population $=0.5740$} \\
\hline House price & Coefficient & Robust standard deviation & T test & $\mathrm{P}>|\mathrm{t}|$ \\
\hline Floor land price & -.1195749 & .1399795 & -0.85 & 0.456 \\
\hline Year 2011 & 935.81 & 770.8847 & 1.21 & 0.312 \\
\hline Year 2012 & 2330.064 & 709.3367 & 3.28 & 0.046 \\
\hline Year 2013 & 9180.405 & 1801.233 & 5.10 & 0.015 \\
\hline Year 2014 & 10035.8 & 1608.382 & 6.24 & 0.008 \\
\hline Year 2015 & 16410.53 & 4205.557 & 3.90 & 0.030 \\
\hline Year 2016 & 22013.44 & 3388.183 & 6.50 & 0.007 \\
\hline Year 2017 & 29877.19 & 4066.68 & 7.35 & 0.005 \\
\hline cons & 20567.58 & 3281.621 & 6.27 & 0.008 \\
\hline sigma_u & & 7785.8853 & & \\
\hline sigma_e & & 4626.0585 & & \\
\hline rho & 7390 & raction of varia & ue to $u$ i) & \\
\hline
\end{tabular}

The time effect symbols are all positive, but there are two periods which are not significant. So we test the annual joint significance. The confidence of the result $\mathrm{F}=0.0117<0.05$, rejects the hypothesis of no time effect.

The panel data model analysis of the individual effect and time effect shows that there is a significant difference in house prices between the four cities of Beijing, Shanghai, Guangzhou and Shenzhen. Beijing's house price is 8,000 yuan per square metre higher than Shanghai's, Guangzhou and Shenzhen are about 4,800 yuan per square metre lower, and 2300 yuan per square metre lower than Shanghai respectively. With the passage of time, the impact of time factors on housing prices is getting stronger and stronger from 2010 to 2017. And the house prices in four cities are increasing with time. The fitting effect of the house price-floor land price model is very good. There is a strong positive correlation between the house price and the land transfer price lagging behind 3 periods. The impact of the rising floor land price on house prices is extremely significant. Without considering the enormous pressure of taxes and fees, the cost of land acquisition is already very high. The real estate enterprises that have to bear the heavy financial costs will not go too far if they claim that the profit margin is only $20 \%$ even with pretentious ingredients. The government and banks did share a huge housing price bonus. 
This model in this paper only pushes forward to the annual average price in 2017 , and the floor price data is only used until 2014. Disturbingly, the floor prices of the four cities in Beijing, Shanghai, Guangzhou and Shenzhen reached 46,426 yuan per square meter , 30,979 yuan per square meter, 25,625 yuan per square meter and 35,963 yuan per square meter, respectively in 2014. While the floor prices of the four cities in Beijing, Shanghai, Guangzhou and Shenzhen had risen sharply to 6,579 yuan per square meter, 50932 yuan per square meter, 45,905 yuan per square meter and 50,397 yuan per square meter in 2017. The increase is faster than before, and no slowdown has yet been observed. The increase is faster than before, and no slowdown has yet been observed. We can imagine that the prices in 2018 and 2019 will surely face a more rapid rise.
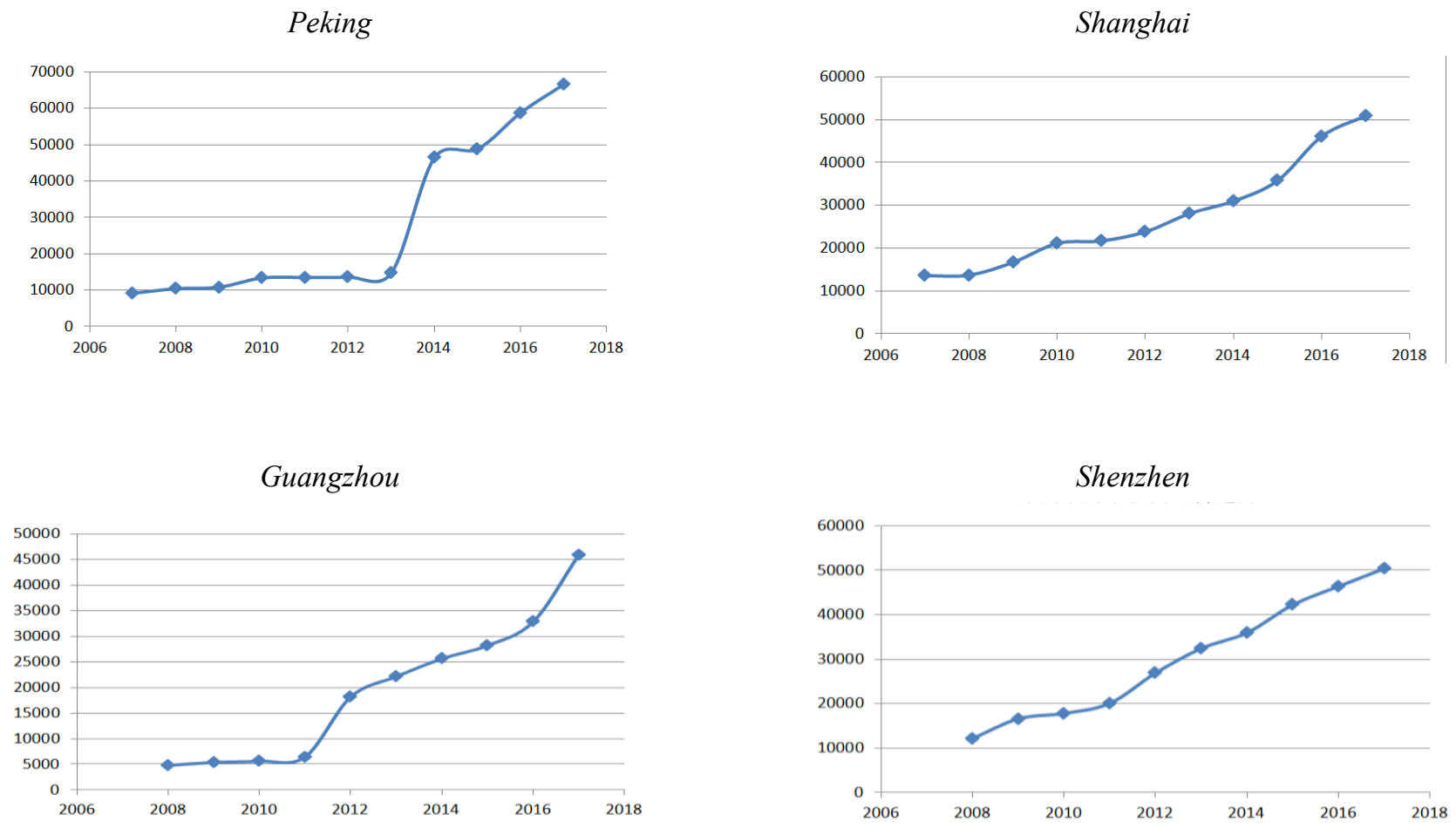

Figure 1. Four Cities' Land-offerring Price

In order to avoid the embarrassing situation of common property houses falling into the same price as general commodity housing but the property right is "disability" and avoid repeating the mistakes of the experience of Huai'an, the government departments urgently need to reduce the land grant, related taxes and fees for common property houses on a large scale, so as not to let the small profits of land finance hurt the hundred-year plan for development of the city.

\section{Model Construction and Solution Analysis Based on Housing Affordability}

\subsection{Compilation of Integration Index of Housing Affordability}

This paper divides the comprehensive ability of housing payment into two aspects, one is the down payment ability of housing (DPA), the other is the monthly mortgage loan payment ability (MPA). In this paper, the two aspects are integrated into the integration index of housing affordability (IIHA).

For ease of description, the paper marks them as follows:

$\mathrm{X}$ : Down payment ability of housing

$y$ : Monthly mortgage loan payment ability

$z:$ Integration index of housing affordability

The integration ability index of housing affordability here is a composite index of the residents' housing payment ability reflected by the down payment ability of housing and the housing loan monthly payment ability. It is determined by the linear combination of the two parts of the down payment ability of housing and the housing loan monthly payment ability. That is to say, the comprehensive index of housing ability $z$ is the weighted average of the two party $x$ and $y$. If the weight of $\mathrm{x}$ and $y$ are $w$ and $1-w$ respectively, then we get: 


$$
\begin{gathered}
z=w x+(1-w) y \\
\mathrm{x}=\mathrm{DPA}=\frac{\begin{array}{c}
\text { Household Savings Balance } \\
\text { Top Payment }
\end{array}}{\text { Monthly Repayment Amount }}
\end{gathered}
$$

Thus, from a statistical point of view, the integration index of housing affordability, as a statistical index, can comprehensively and objectively reflect the whole process of Chinese residents' purchase of houses. Therefore, the index can be used as a composite index to measure the level of housing affordability of Chinese residents, which has more connotations than the previous three traditional indicators. The calculation of the above integration index $\mathrm{z}$ involves the following three parts. The first part is about family income and expenditure. Let $F S$ expresses household savings balance, $F I$ denotes household annual disposable income, $F C$ denotes household annual consumption expenditure, $H C$ denotes household annual housing consumption expenditure, and the annual basic household consumption expenditure is $L C=F C-H C$. The second part is about the market value of housing. $H P$ and $H A$ are used to express the average selling price and the average area of each house respectively. If the down payment ratio of house purchase is $\alpha$, then the market value of housing is $P=H P \times H A$ and the down payment is $D P=\alpha \times P$. The third part is about the monthly repayment amount of housing mortgage loan $M P$. If the monthly interest rate of housing mortgage loan is $i$ and the age of loan is $n$, the monthly repayment amount of equal repayment is as follows:

$$
M P=P \cdot(1-\alpha) \cdot \frac{i \cdot(1+i)^{12 n}}{(1+i)^{12 n}-1}
$$

Therefore, the down payment capability $\mathrm{x}$ and the monthly payment ability $y$ in the comprehensive housing payment capacity can be expressed as:

$$
\begin{aligned}
& x=D P A=\frac{F S}{\alpha \cdot P} \\
& y=M P A=\frac{(F I-F C+H C) / 12}{P \cdot(1-\alpha) \cdot i \cdot(1+i)^{12 n} /\left[(1+i)^{12 n}-1\right]}
\end{aligned}
$$

The size of integration index a of housing affordability is affected by weight $w$, down payment ability $x$ and monthly payment ability $y$ these two parts. Under the given weight $w$, the value of $z$ only depends on the value of $x$ and $y$. Obviously, for the integration affordability, the greater the value of $z$, the stronger the housing affordability of residents is, and vice versa.

Firstly, we consider the impact of $x$ and $y$ changes on the comprehensive payment capability index $z$. When $x$ and $y$ increase at the same time, that is, the down payment ability $D P A$ and the monthly payment ability MPA both increase, then the integration index $z$ of residents' housing affordability also increases correspondingly, which means that residents' housing affordability increases accordingly. Conversely, when $x$ and $y$ decrease at the same time, the affordability $z$ also decreases accordingly. This shows that there is a positive correlation between the simultaneous changes of integration payment ability $z$ and down payment ability $x$ and monthly payment ability $y$. Furthermore, when $y$ is fixed, the integration ability $z$ increases (decreases) as the down payment ability $x$ increases (decreases). Similarly, when $x$ is fixed and $y$ becomes larger (decreases), then the comprehensive ability $z$ increases (decreases) correspondingly. Based on the analysis of the influence direction of $x$ and $y$ on $z$, we can further discuss the impact of one of the two on $\mathrm{z}$ and easy to get the followings:

$$
\frac{\partial z}{\partial x}=w, \frac{\partial z}{\partial y}=1-w
$$

The determination criteria of down-payment ability and monthly payment ability are the comparison of $D P A$ and $M P A$ with 1 . When down-payment ability $D P A \geq 1$, the residents have strong down-payment ability of housing, and family savings accumulation can bear down-payment of housing. When monthly payment ability $M P A \geq 1$, the residents have strong monthly payment ability, and the monthly residual income of the family can afford the monthly payment of the house purchase. When DPA and MPA are both less than 1, it shows that residents have obvious inadequacy of affordability in purchasing houses. For different income groups and different cities, down payment ability $D P A$ and monthly payment ability $M P A$ are also different and should be treated differently. According to the different values of DPA and MPA, the housing capacity of residents can be divided into the following three types: strong affordability type, medium affordability type and weak affordability type.

Among them, the strong payment ability, which $D P A$ and $M P A$ of the family are all greater than or equal to 1 . The 
family's savings balance and residual income can fully pay the down payment and monthly loan repayment. This type of family does not have housing payment problems, and it is a more ideal purchase status. Usually, families with strong affordability will emerge in areas where housing prices are lower or where housing prices are lower to household incomes relatively.

The DPA and MPA of weak payment ability families are less than 1, and the savings balance of households can not bear the down payment of house purchase. Besides, the residual income of households can hardly pay the monthly repayment of house purchase. There are serious housing payment problems in such families, which is the worst case in the process of house purchase. Housing prices exceed the income level of residents to a large extent. Families with weak affordability will appear in areas with large population, high house prices or economically backward areas with low income.

Wealth dependence type. This type of housing affordability family's $D P A$ is greater than or equal to 1, while $M P A$ is less than 1. In the process of purchasing a house, the family's savings balance can pay down payment, but the family's residual monthly income is difficult to bear the monthly loan repayment, which is a type of medium housing affordability. Families of this type of payment usually have the following characteristics: the family has abundant savings, but the family members have no fixed income sources, and the monthly income is unstable. This type of household also usually occurs in areas with slow economic development as well as low income and low expenditure, but high savings.

Income dependence. The $D P A$ of this type of housing affordability family is less than 1 , while $M P A$ is greater than or equal to 1 . The family's savings can not pay the down payment of housing, but the family's monthly income is enough to bear the monthly loan repayment, which is also a type of medium payment capacity. This situation is more common in families where the main body of housing consumption is the salaried class. The salaried class has a fixed job, stable income, and can bear the monthly loan repayment. But the savings are low, which is insufficient to pay the down payment for housing. Such families also tend to occur in areas where housing prices are lower than those with lower household incomes. In a word, both down payment ability $D P A$ and monthly payment ability $M P A$ are included in the evaluation system of housing affordability, and integrated into a integration index of housing affordability, which makes full use of the advantages of traditional housing affordability index $H A I$ and residual income method RIA. Moreover, this method not only takes into account the down payment ability and the monthly payment ability, but also distinguishes them according to the need, which can measure the comprehensive payment ability of residents' house purchasing comprehensively and objectively.

For the sake of simplicity, it may be assumed that down payment ability and monthly payment ability are equally important, because they are indispensable links in the process of purchasing houses. So we let $w=0.5$.

At this time, the formula of housing affordability integration index is $z=0.5 x+0.5 y$. On the other hand, in real house purchasing, although down payment ability $x$ and monthly payment ability $y$ are both essential steps in the process of house purchasing. But the importance of them may be different for families with different housing affordability when considering the difference of rigid constraints of order in the process of house purchasing. The down payment is more important because it needs to be paid in advance in order to carry out the follow-up link of house purchase and loan repayment. Most of the families are wage earners with relatively fixed incomes, especially for income-dependent families. They have relatively less pressure on monthly payment, and down payment may be more important to them. Full one-time down payment is the main obstacle to their purchase. At this time, we should give more weight to the down payment capability $x$. For wealth-dependent households, monthly payment ability $M P A$ is relatively more important, because such households may have few fixed income sources on schedule, and the pressure of monthly payment to repay loans may be greater. Therefore, for this type of family, the monthly payment ability $y$ should be given greater weight. Meanwhile, other specific weight selection should be combined with the specific property and income composition of different households to determine.

\subsection{Determination of Reasonable Housing Expenditure}

The ratio of housing expenditure to residents' disposable income has always been an important indicator to measure the quality of life. However, under the high pressure of about $40 \%$ for a long time in Beijing, Shanghai, Guangzhou and Shenzhen, they are facing enormous housing pressure. Under special conditions, the proportion of housing expenditure even reflects the gap between rich and poor and income pressure more prominently than Engel coefficient. It can be seen that the proportion of residential expenditure in the four cities of Beijing, Shanghai, Guangzhou and Shenzhen is not optimistic. The productivity of residents is firmly bound by housing, and they even have to struggle for the basic human right of living. If we refer to the distorted proportion, it will result in a greater waste of resources. Therefore, policymakers need a reasonable proportion of housing expenditure urgently.

The Organization for Economic Cooperation and Development (OECD), including the major developed economies in 
the western world, has published YBLI (Your Better Life Index) since 2013, which is a comprehensive index reflecting and comparing the economic development of different countries from the perspective of the quality of life of residents. It has attracted the attention of senior think tanks, including the Chinese Academy of Social Sciences, the International Bureau of Statistics and so on. One of the important indicators is HE (Housing Expenditure), which includes the actual and estimated housing rent and the percentage of household daily maintenance services to the disposable income after the total adjustment. Referring to this important index of western developed countries, this paper hopes to use a suitable number to measure the affordability of house purchasing, so that the housing burden of young talent groups can be reduced to the average level of developed countries' economies, solving the pricing problem of common property houses.

Table 2. HE data of 34 OECD members (show only part)

\begin{tabular}{ccccccc}
\hline Time & Country & HE (\%) & Time & Country & HE (\%) & $\cdots$ \\
\hline 2017 & Korea & 15 & 2016 & Korea & 16 & $\cdots$ \\
2017 & UK & 24 & 2016 & UK & 23 & $\cdots$ \\
2017 & US & 18 & 2016 & US & 19 & $\cdots$ \\
\hline
\end{tabular}

Above are HE data for 34 OECD members (shown only part) and we can see that the data vary and fluctuate from year to year. The method of two-way ANOVA analysis of 170 data from five groups was conducted to determre qualine whether there were qualitative differences in HE between developed economies and whether there weitative changes in the past five years.

Model assumption: national factors and time factors have no significant impact on HE index.

Structure test statistics:

Total square sum:

$$
S S T=\sum_{i=1}^{k} \sum_{j=1}^{r}\left(x_{i j}-\bar{X}\right)^{2}=S S R+S S C+S S E
$$

Among, SSR $=\sum^{k} \sum^{r}\left(x_{i}-\bar{x}\right)^{2}$ represents the error square produced by time factor, SSC $=\sum_{i}^{k} \sum_{j=1}^{r}\left(x_{j}-\bar{x}\right)^{2}$ represents the error square produced by country factor. SSE represents the sum of squares of random errors.

On the basis of above, the sum of squares is divided by the corresponding degree of freedom, that is, the mean square:

$$
M S R=\frac{S S R}{k-1}, M S C=\frac{S S C}{r-1}, M S C=\frac{S S E}{(r-1)(k-1)}
$$

The $\mathrm{F}$ test for $F=\frac{M S R}{M S E}$ 和 $F=\frac{M S C}{M S E}$ was compared with the confidence level of 0.05 , the results are as follows:

\begin{tabular}{cccccc}
\hline \multicolumn{7}{c}{ Intersubjective effect test } \\
\hline Modified model & Cluster square sum & Free degree & Mean square & F test & Saliency \\
Intercept & 859.329 & 37 & 23.225 & 29.093 & .000 \\
& 76235.294 & 1 & 76235.294 & 95496. & .000 \\
Time factor & 3.824 & 4 & .956 & 260 & \\
Country factor & 855.506 & 33 & 25.924 & 32.474 & .000 \\
Deviation & 105.376 & 132 & .798 & & \\
Total & 77200.000 & 170 & & & \\
Correction totals & 964.706 & 169 & & &
\end{tabular}

The significance of $\mathrm{F}$ test of time factor (year) is $0.315>0.05$, rejecting hypothesis. The significance of $\mathrm{F}$ test of country factor (country) is $0.00<0.05$, not rejecting hypothesis. Empirical evidence shows that the HE index of each country is stable from 2013 to 2017, while there are differences among different countries. In order to explain the clustering effect of each factor in detail, the homogeneity subset test of the two factors is carried out. Because there is no statistical difference in time factors, only the influence of national factors is shown (part): 


\begin{tabular}{|c|c|c|c|c|c|c|c|}
\hline $\begin{array}{l}\text { OECD } \\
\text { country }\end{array}$ & $\mathrm{N}$ & $\begin{array}{c}1 \\
\text { subset } \\
\end{array}$ & $\begin{array}{c}2 \\
\text { subset } \\
\end{array}$ & $\begin{array}{c}3 \\
\text { subset } \\
\end{array}$ & $\cdots$ & $\begin{array}{c}16 \\
\text { subset } \\
\end{array}$ & $\begin{array}{c}17 \\
\text { subset } \\
\end{array}$ \\
\hline Korea & 5 & $15.8 \%$ & & & $\cdots$ & & \\
\hline Norway & 5 & & $17.4 \%$ & & $\cdots$ & & \\
\hline Chile & 5 & & $18.2 \%$ & $18.2 \%$ & $\cdots$ & & \\
\hline Americ & 5 & & & $18.6 \%$ & . & & \\
\hline Portugal & 5 & & & $18.8 \%$ & $\cdots$ & & \\
\hline Estonia & 5 & & & $19.0 \%$ & $\cdots$ & & \\
\hline NewZealand & 5 & & & & $\cdots$ & $24.6 \%$ & \\
\hline Slovaka & 5 & & & & $\cdots$ & $25.0 \%$ & $25.0 \%$ \\
\hline Czech & 5 & & & & $\cdots$ & $25.2 \%$ & $25.2 \%$ \\
\hline Greece & 5 & & & & $\cdots$ & & $25.8 \%$ \\
\hline
\end{tabular}

Thirty-four countries were clustered into 17 groups, with the lowest HE index being Korea (15.8\%) and the highest HE index being Greece, Czech Republic and Slovakia (25\%-25.8\%). The empirical test of two-factor variance comparison shows that the HE indicators of developed countries are stable values with very small fluctuations, which are differentiated according to the level of economic development and the characteristics of national conditions. The developed country like United States and Norway are around $18 \%$, but $21 \%$ of Germany and $22 \%$ of the United Kingdom.

This paper suggests that China's first-tier cities adopt the long-term constant proportion of residential expenditure as the criterion for the pricing of shared property housing, while the per capita GDP of Beijing, Shanghai, Guangzhou and Shenzhen is close to $\$ 20,000$, which can entirely refer to Czech and Slovakia, which have the same level of per capita GDP, to determine the proportion of residential expenditure as $25 \%$. It is in line with the minimum level of security in OECD countries and can guarantee common property rights housing buyers a standard of living in nearly developed economies.

\subsection{Determination of Reduction Interest Rate}

This paper collects the evolutionary map of per capita income distribution in Beijing. According to the burden index of $25 \%$, the 30 -year discount price of ordinary housing loans is calculated. Thirty years is not a small number. The interest rate of personal mortgage loan in bank is 5\%-7\%. Even if the mortgage method of 5\% of the interest rate and the equal principal and interest payments is adopted, the principal and interest of the loan are almost the same every month. The calculation formula of the equal principal and interest repayment of the mortgage is as follows:

$$
\text { Int }=A \cdot \frac{r \cdot(1+r)^{\wedge} t}{(1+t)^{\wedge} t-1}
$$

Among them, Int represents the principal and interest of monthly repayment, $A$ represents the amount of loan, $r$ represents the monthly interest rate, $t$ represents the number of months repayment. Even at an annual interest rate of $5 \%, 30$ years of loan, the monthly repayment principal and interest and the amount of loan reach $0.54 \%$, mortgage maturity repayment principal and interest and $1.93 \mathrm{~A}$, the burden of interest is almost the same as the amount of loan. The mortgage pressure of young people is obvious and needs to be alleviated urgently.

Referring to the pricing model of sustainable public debt, the pricing conversion model of common property housing is established as follows:

$$
P=R \cdot Y / I R
$$

Among them, $P$ represents the individual burden of common property housing, $R$ represents the optimal burden ratio, $Y$ represents personal income, IR represents the rate of return on investment.

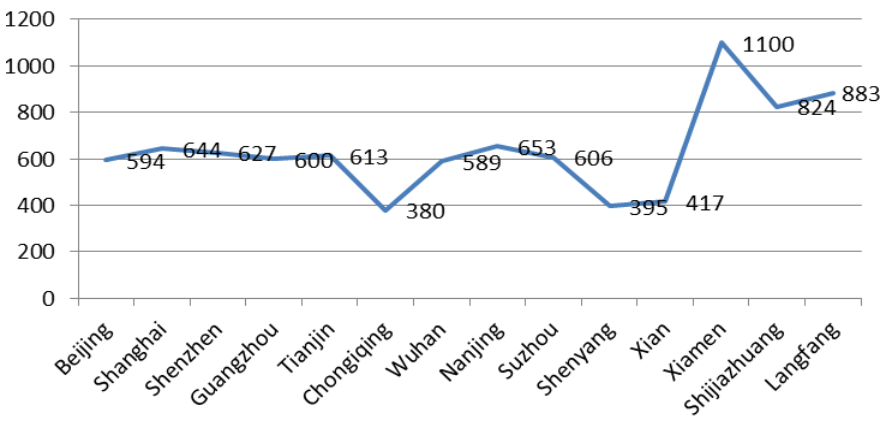

Figure 2. Price-Rental Ratio 
Above is the average price-rent ratio of 15 cities from 2013 to 2017. It can be seen that the four first-tier cities in Beijing, Shanghai, Guangzhou and Shenzhen are in the range of 594-644, that is, the annual return on real estate investment is $1.86 \%-2.02 \%$. Although the return on real estate investment is still much lower than that of $5 \%-6 \%$ in Europe. But using $2 \%$ as the standard of return on investment is the most reasonable in Beijing, Shanghai, Guangzhou and Shenzhen. The rate of return is reasonable in Beijing, Shanghai, Guangzhou and Shenzhen. The optimal burden ratio applies $25 \%$ which is in the previous passage, and the return on investment is $2 \%$. While individual income can be adjusted according to the average income or the previous $20 \%$ or $10 \%$. The average income of the residents in Beijing, Shanghai, Guangzhou and Shenzhen these four cities is shown in the figure as follows, of which the distribution of income in Beijing is more detailed.
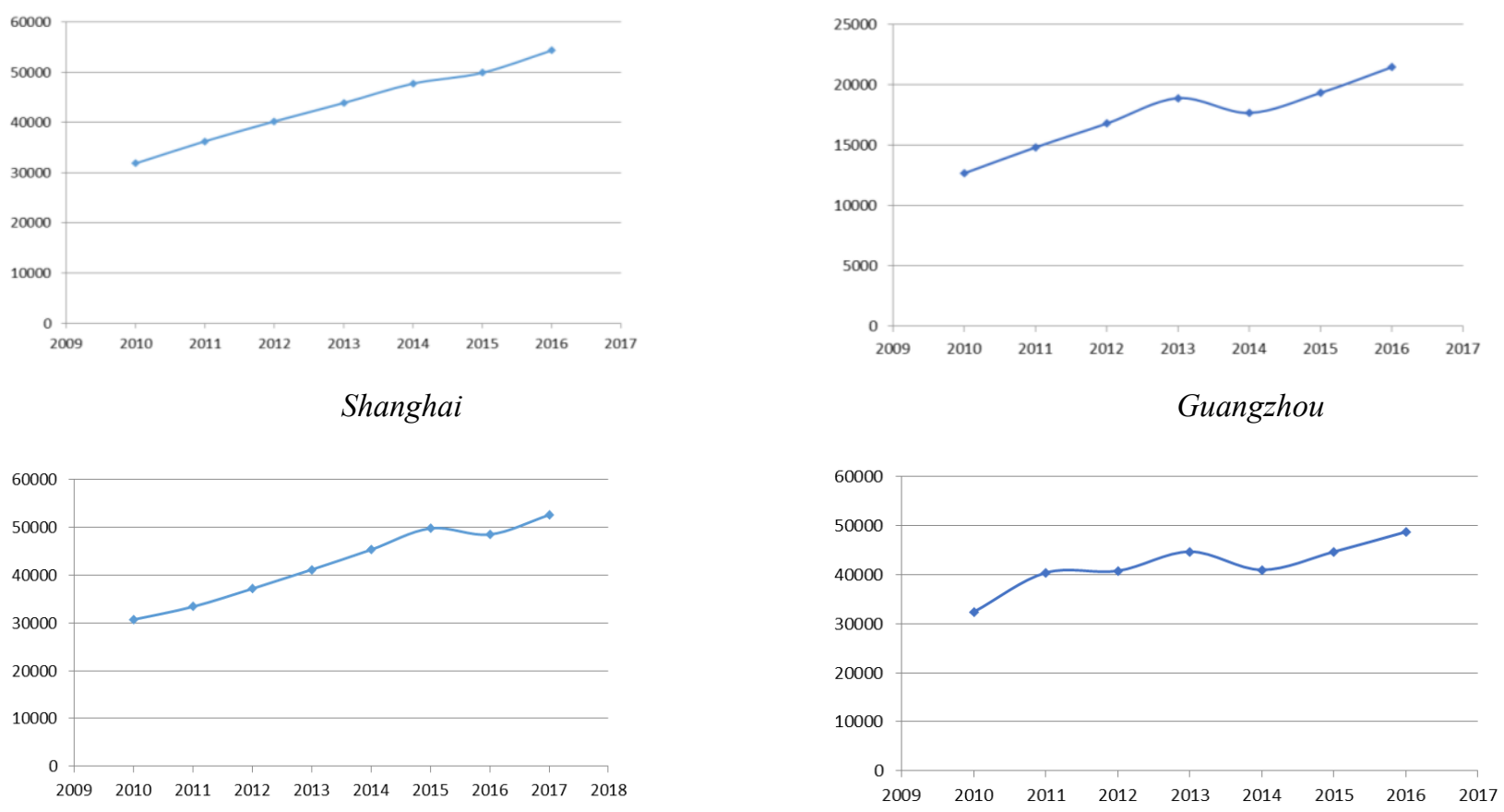

Peking

Shenzhen

Figure 3. Disposable Income

Taking Beijing's common property housing pricing as an example, the average income or middle and high income can be used as the calculation standard. Referring to the disposable income of Beijing residents in 2016, using 50,000 yuan or 65,000 yuan as the pricing criteria for two different classes of common property housing, it is calculated as follows: 1 . The personal burden of the first type of housing is 620,000 yuan; 2 . The personal burden of the second type of housing is 820,000 yuan, and the total price of the common property housing is $50 \%$ of the individual and the government, respectively. The total price of common property housing is 1 million 240 thousand yuan and 1 million 620 thousand yuan respectively.

\subsection{Reasonable Pricing Proposal is Recommended}

The specific pricing of Beijing, Shanghai, Guangzhou and Shenzhen is as follows:

\begin{tabular}{ccc}
\hline City & Average income reference burden (yuan) & Middle and high income reference burden (yuan) \\
\hline Beijing & 620,000 & 820,000 \\
Shanghai & 675,000 & 890,000 \\
Guangzhou & 275,000 & 364,000 \\
Shenzhen & 450,000 & 595,000 \\
\hline
\end{tabular}

This part of the property right value of the individual burden is suggested to fixed, while the other part of the property right held by the government can be flexible. We can choose different proportion of high or low, and build different grades and different quality of common property right housing by adjusting this proportion. For example, the Beijing municipal government has $50 \%$ or $80 \%$ property rights, and the total value of the property rights housing is 1 million 640 thousand yuan and 4 million yuan, respectively. Then it can be sold to people of different grades that need to be introduced, thus achieving effective allocation of resources.

In questioning the fact that personal income refers only to immediate wage income and neglects the long-term income growth in the future, especially that the owners of common property housing are young talents with great potential for 
development, which will greatly underestimate the housing price. This problem is actually excessive and there are 3 main reasons for this problem:

(1) The cost of government investment has been greatly reduced: the price of common property houses is cheaper for both buyers and the government. The government can "self-production and self-sale", using the land transfer fee and tax charges collected by real estate as capital contribution to buy property rights of real estate.

(2) The ratio of income to cost of long-Rent apartments owned by the government has been greatly increased: this paper always suggests that the government repurchase the common property houses and transform them into high-quality long-Rent apartments, which can generate low-risk, high-flow and long-term cash flow income in the coming decades, and this part of rental income will grow synchronously with the future per capita income of residents. It is the most valuable investment that the government keeps expanding its balance sheet with low liabilities, but keeps its balance sheet not shrink by overvaluation.

(3) The housing cost pressure of the buyers is still not low: first, the mortgage repayment pressure mentioned above in this paper, the buyers bear heavy compound interest, almost twice the amount of loans to repay the heavy principal and interest. The difficulties of the buyers in buying houses are actually greatly underestimated. Because the main energy of young talents is work, investment and entrepreneurship. The cost of the mistake is high and the pressure on the capital chain is enormous. The lower the living expenditure, the better. Only in this way can young people have no scruples and devote their energies to work and entrepreneurship to the greatest extent, instead of being exhausted by firewood, rice, oil and salt.

\section{Conclusion \& Policy Recommendation}

\subsection{Reducing Land-Transferring Fees and Relative Taxes}

This paper suggests government to substantially reduce land-transferring fees, land and property taxes, supplemented by collective-land entry policy, the national unified land ticket system and consecutive land supplement offered by state-owned companies. According to the pricing plan proposed in this paper: a 1.64 million yuan shared property housing, 60 square meters of standard two-bedroom and one-bedroom small-sized apartment, the average house price is 27,300 yuan / square meters, and the land price of the four cities in 2018 is more than 40,000 / square meter, which is obviously very unreasonable. It is necessary to encourage real estate developers to gurantee quality and quantity, and not to make the shared property house be lower quality public rental house. It is recommended to ensure that the real estate agent obtains about $35 \%$ of the house price as income. This part of the operating income can be deducted from income tax and financial expenses but aintain a certain profit, then the land-transferring fee plus all deed tax stamp tax planning approval fees and other fees should be significantly reduced to 19,000 yuan / square meters, Beijing's 2016 floor price from the average price of 24,000 yuan soared to 60,000 yuan / square meters, It does not include the VAT use tax, etc. It can be seen that the "bidding and auctioning" is so weak to the "land king"- Most expensive estate.

\subsection{Closed Operation and Control Flow}

Although this paper concedes to Beijing's pricing has its drawbacks,and needs to be considered, but its proposed closed operation is a very commendable highlight, which is one of the biggest advantages that distinguish it from Limits houses and Economical houses. It guarantees that the shared property houses can meet the protection needs and does not repeat the mistakes as speculative tools; property rights are the most powerful legal guarantee, avoiding the gross interference of administrative orders and maximizing the impact on the real estate market. This paper suggests that the newly-built or under-constructed shared-property housing will be closed and operated, and the government will completely control its circulation, and the closed operation will be regarded as an unshakable basic condition. It is recommended that all government-owned or government-owned agency agencies have financial conditions. Buy back property rights, rather than simply accepting the next batch of eligible housing needs. There are two advantages to doing this: on the one hand, it will generate stable cash income in the future, from a large number of people with the most potential for consumption, which is an extremely low-risk credit asset, greatly optimizing the balance sheet; On the other hand, avoiding the cumbersome second-hand house depreciation estimates, the use of shared property housing to resell is subject to depreciation estimation, the sale is not as easy as the new house, but also to pay some resources to invest in the new assessment, easy to breed rent-seeking behavior, potential hidden dangers .

\subsection{Strict Qualification Censorship}

The shared property housing must be supplemented by the most stringent qualification review mechanism, giving priority to the most urgent talent needs, that is, the "no-class" young scientists, engineers, and senior management personnel who have practical housing purchase difficulties, and housing must not be considered. The qualified applicants may consider transparent disclosure, and the type, model house and supporting facilities will be fully announced. This link often has the problem of rent-seeking behavior that distort the allocation of resources. The case of opening a BMW to apply for public rental housing has occurred from time to time, causing the people to be dissatisfied 
with the tragedy. Only use the most rigorous review, the most transparent publicity to fight rent-seeking behavior, and ensure that valuable state-owned assets are invested in the most efficient places.

\subsection{Flexible Property Shares}

The shareholding ratio of property rights is not a rigid red line, but should be a conditional grading system. The key attracting talents can consider the government to hold higher property rights and reduce the heavy burden of young people. For example, the key talents such as the Yangtze River Scholars and the Thousand Talents Programmer can consider individuals of 1:9. Therefore, for the issue of the proportion of government property rights, the shared property houses will play a huge role in the welfare housing in the planned economy era.

\subsection{Gradually Replace Economical House \& Limits House}

The biggest drawbacks of the two limited houses and economical house is that the government does not control the property rights of the real estate and loses control over the legal effect. No matter how to limit the resale period and the selling price, the two restricted houses and the economical house will change into ordinary The circulation of commercial housing is in the midst of a tide of circulation, and the government is unable to regulate it. This is actually a guarantee for the speculators to make a wedding dress, and it has paid a huge economic cost. It is extremely difficult to realistically hope that the ideal conditions for the balance of supply and demand in the market mechanism will be extremely difficult in the real world. The Matthew effect in the real estate market is intensifying, and the share is concentrated in dozens of giant oligopolistic enterprises. The market itself is full of asymmetric information and rent-seeking. Behavior, price is extremely sensitive to expectations, the basic assumptions of a perfect market are difficult to meet, and how long will the self-regulation cycle take? 5 years, 10 years or 15 years? The heavy social governance costs behind it are self-evident.

The regulation of housing prices is necessary and urgent. The crucial suggestion is that the government should rely on huge land supply to eliminate the "land kings", use the land ticket system and collective land to suppress land prices from the supply side; use public rental housing and shared property housing to alleviate demand. Such as the kinds of housing means to mobilize the low-income class and the middle-income and high-income youth groups, to separate this part of the most promising home buyers from the free market, and suppress house prices from the demand side. Supply and demand policy works, then market expectations reverses, rather than rely on the shouting slogan report plan, so that prices return to the normal range.

\section{References}

Andersson, R., \& Turner, L. M. (2014). Segregation, gentrification, and residualisation: from public housing to market-driven housing allocation in inner city Stockholm. International Journal of Housing Policy, 14(1), 3-29. https://doi.org/10.1080/14616718.2013.872949

Bright, S., \& Hopkins, N. (2011). Home, meaning and identity: Learning from the English model of shared ownership. Housing, Theory and Society, 28(4), 377-397. https://doi.org/10.1080/14036096.2010.527119

Chen, F. L. (2014). Research on the initial distribution and adjustment of the proportion of property rights of shared property (Master's thesis, University of Wuhan, Wuhan, China).

Cowan, D., Carr, H., \& Wallace, A. (2018). "Thank heavens for the lease": histories of shared ownership. Housing Studies, 33(6), 855-875. https://doi.org/10.1080/02673037.2017.1408782

Deng, H. G., \& Wang, Y. B. (2015). Discussion on the pricing mechanism of common property housing in China. Price theory and practice, (7), 34-36.

Deng, X. P., Duan, Y. Z., Yuan, J. Y., \& Zhang, X. (2012). Research on the shared property rights distribution of affordable housing under PPP mode. Journal of Engineering Management, (6), 81-86.

Disney, R., \& Luo, G. (2017). The Right to Buy public housing in Britain: A welfare analysis. Journal of Housing Economics, (35), 51-68. https://doi.org/10.1016/j.jhe.2017.01.005

Hegedüs, J., Lux, M., \& Horváth, V. (Eds.). (2017). Private Rental Housing in Transition Countries: An Alternative to Owner Occupation?. Palgrave Macmillan, London. https://doi.org/10.1057/978-1-137-50710-5

Jiang, M. D, Zhang, F. P., \& Qin, C. (2015). Research on pricing model of shared property houses--taking Huai'an and Huangshi as examples. Enterprise Herald, (13), 7-9.

Lee, H., \& Ronald, R. (2012). Expansion, diversification, and hybridization in Korean public housing. Housing Studies, 27(4), 495-513. https://doi.org/10.1080/02673037.2012.677018

Mount, I. (2015). Shared ownership: A solution to the affordable housing conundrum? Fortune.Com, N.PAG.

Peng, N. (2014). Shared property rights seek a win-win situation in the balance of interests. Sichuan Party Building: 
Urban Edition, (7), 40-41.

Schmitz, P. W. (2017). Incomplete contracts, shared ownership, and investment incentives. Journal of Economic Behavior \& Organization, (144), 153-165. https://doi.org/10.1016/j.jebo.2017.09.021

Shan, X. Q., Li, Y. C., \& Wang, H. Y. (2014). Design of property rights structure of public rental housing based on three parties' satisfaction-Taking Chongqing City as an example. Construction Economy, (12), 65-69.

Stegman, M. A. (2017). The Housing Market Cannot Fully Recover Without a Robust Rental Policy. BCJL \& Soc. Just., $37,395$.

Tang, W. (2012). Development and Prospect of Shared Property in Huai'an City. Northern Economy, (18), 78-79.

Wang, Y. B. (2016). Research on pricing and property rights of shared property housing (Master's thesis, Central China Normal University, Wuhan, China).

Wang, Z. B. (2014). Analysis of the common property housing system based on property rights theory. Economist, (7), 68-70.

$\mathrm{Xu}, \mathrm{H}$. (2017). Research on the development model of shared property housing-taking Beijing as an example. Price theory and practice, (12), 54-57.

$\mathrm{Xu}, \mathrm{Z}$. C., \& Zhang, Q. L. (2018). Research on the pricing of shared property housing-taking Beijing as an example. Chinese prices, (4), 62-65.

Zeng, J. X. (2013). Empirical study on rent pricing and subsidy mechanism of public rental housing (Doctoral dissertation, Qingdao Technological University).

Zhao, Q. (2015). Analysis of current status of property ownership in Shanghai and policy recommendations. Modern Business, (5), 251-252.

Zhou, W. (2009). Research on the pricing and management model of affordable housing based on game theory (Master's thesis, Jiangxi University, Jiangxi, China).

Zhou, Y, \& Sun, W. (2017). Research on Rent Pricing Method of Common Equity-type Public Rental Housing in China's BOT Mode-Taking Wuhan Public Rental Housing as an Example. Modern Business, (20), 82-85.

\section{Copyrights}

Copyright for this article is retained by the author(s), with first publication rights granted to the journal.

This is an open-access article distributed under the terms and conditions of the Creative Commons Attribution license which permits unrestricted use, distribution, and reproduction in any medium, provided the original work is properly cited. 